J O U R N A L

$\mathrm{O} F \bullet \mathrm{B} A \mathrm{~L} T \mathrm{I} C$

$S$ C I E N C E

EDUCATION

\section{ISSN 1648-3898 /Print/ ISSN 2538-7138}

\title{
ASSESSING PRE-SERVICE TEACHERS' RECEPTION AND ATTITUDES TOWARDS VIRTUAL LABDRATIRY EXPERIMENTS IN LIFE SCIENCES
}

\author{
Mafor Penn, \\ Lydia Mavuru
}

Abstract. This research reports the assessment of pre-service teachers' reception and attitudes towards virtual laboratory
\end{abstract} experiments in Life Sciences with the aim of advancing adaptability to digital learning. Using sequential mixed-methods in a quasi-experimental design, 68 pre-service teachers in the 3rd year of a Bachelor of Education (B.Ed) program were surveyed before and after virtual learning interventions. This phase was followed by qualita-

tive data gathering using focus group interviews with all participants. Findings from quantitative data analysis revealed a positive significant difference in pre-service teachers' attitudes towards virtual laboratory experiments post learning interventions. From qualitative data pre-service

teachers found the progression from using only traditional to including virtual experiments was useful in enhancing their conceptual understandings of Life Sciences

concepts, convenience, inquiry-based learning, self-directed and autonomous learning. However, pre-service teachers noted that using virtual laboratories did not significantly develop their science process skills and as a result could not replace the experiences in a traditional biology laboratory. The implications of these findings project virtual laboratories as a supporting tool for experimentation in Life Sciences especially within and post

the COVID-19 pandemic where issues of social distancing pose a threat to collaborative and inquiry-based science learning. Recommendations from these findings are discussed herein.

Keywords: inquiry-based learning, life sciences, pre-service teachers, virtual laboratory experiments

Mafor Penn, Lydia Mavuru University of Johannesburg, South Africa

\section{Introduction}

In a fast changing world infused with novel and innovative practices in the field of science and technology, the global science education discourse is evolving in preparing both teachers and learners who are versatile, adaptable and progressive. Technology-enhanced science learning has gained grounds over the last two decades of science education reforms globally and even nationally in South Africa (Department of Education [DoE, 2004]; National Research Council [NRC], 2012; Vandeyar, 2015). Several learning technologies have been advocated as alternative pedagogical tools for enhancing students' interest, attitudes, and motivation in science subjects (Esquembre, 2015; Hsu et al., 2017). The subject Life Sciences (herein also referred to as biology) is characterized by the study of living things and the systemic processes that occur in all living organisms (Umar, 2011). Life Sciences serve as the baseline for a wide range of science, technology, engineering and mathematics (STEM) disciplines including biochemistry, medicine, biotechnology, food technology and pharmacy, just to name a few.

In understanding some of the complex processes that are inherent to biological systems, it is relevant for students to engage in experimental learning to enhance visualization of micro-scientific phenomena and their conceptual understandings (Duyilemi et al., 2014; Umar, 2011). Experimental and laboratory-based learning also provide an opportunity for students to test hypothesis, manipulate variables and solve complex scientific problems through inquiry (Großmann \&Wilde, 2019). Unlike virtual laboratories which are online or offline computer-based applications, a traditional science laboratory refers to a physical hands-on laboratory with real objects, reagents, and materials (Hawkins \& Phelps, 2013). As oppose to a virtual laboratory which can be accessed from anywhere, students must go to the location of a traditional science laboratory to physically experiment and interact with scientific phenomena, individually or in groups (Hawkins \& Phelps, 2013; Vasiliadou, 2020). This research aimed at assessing pre-service teachers' reception (the willingness to use) and attitudes towards virtual laboratory experiments in Life Sciences. The assessment constituted first steps in the integration of virtual laboratories in pre-service Life Sciences teachers' professional development. 
Looking at attitudes, several studies of different affective domains in science education have shown that attitude is closely related to the achievement students attain in a subject (Can, 2012; Chua \& Karpudewan, 2017; Koballa \& Crawley, 1985). Some researchers argued that achievement as well as the nature of instruction are key factors, which affect students' attitudes towards science subjects and vice versa (Simpson \& Oliver, 1990). Attitude is defined as a mental and emotional entity that characterizes a person's actions or thoughts towards a subject (Perloff, 2016). For several decades in modern science, attitude is one of the affective domains, which has been extensively investigated (Francis \& Greer, 1999; Kaur \& Zhao, 2017; O'Brien \& Porter, 1994). This is because attitude correlates strongly with other constructs like, science learning, achievement and even orientation towards careers in science (Can, 2012; Chua \& Karpudewan, 2017; Otor \& Achor, 2013). One of the key assumptions made for the surrent study was that, if pre-service teachers (also referred to as students), showed positive attitudes towards virtual experimentation in Life Sciences learning, conceptual understandings and subsequently achievement in Life Sciences content tests will improve.

\section{Research Problem}

The problem addressed in this research has a dual facet to it. Firstly, it was noted that despite the advocacy for experimental and inquiry-based learning in science education, laboratory-based learning is challenged in several learning contexts ranging from school to tertiary levels. Experimental learning, for science instruction, is resource-laden and usually cost demanding to enact especially in the Life Sciences where materials including reagents, specimens, human and other resources are costly and not always available. Even when these resources are available, other factors including overcrowding of laboratory spaces, time limitations and ethical consideration related to biological specimens (Hsu et al., 2017; Umar, 2011) affect students' accessibility to the content they need to grasp (Naidoo \& Paideya, 2015). The second dimension to the problem relates to the negative attitudes displayed towards science subjects as a whole and laboratory learning in particular. In practice students may tend to show negative attitudes towards science laboratory learning due to certain difficulties including incomprehensible processes, self-doubt, visual disturbances with body fluids like blood/cell sap, difficulty in using apparati, and limited instructional guidance to scaffold understandings of certain concepts which may limit their engagement (Potkonjak et al., 2016).

\section{Research Focus}

Introducing the use of virtual laboratories in Life Sciences was part of an inquiry-based learning (IBL) agenda for adding to pre-service teachers' learning experiences and post-qualification pedagogical repertoires in a fast changing world. The domain of experimental learning constitutes part of the widely advocated IBL agenda as a means to foster critical thinking, problem solving and scientific literacy for students (Lederman, 2009; Lee \& Anderson, 2013). With the several challenges associated to traditional experimentation in science learning, alternative strategies were considered to incorporate experimentation as part of pre-service teachers'learning of Life Sciences concepts. It was observed that though traditional resources are limited, more schools and tertiary institutions are becoming digitalized, and equipped with computers, smart boards, and tablets. It was also noted that not many studies in the South African context have investigated attitudes towards virtual laboratory experiments in Life Sciences, especially for pre-service teachers. Hence the need to assess reception and attitude shifts towards virtual experimentation in the Life Sciences.

\section{Research Aim and Research Questions}

The aim of this research was to assess pre-service science teachers' attitudes towards virtual experiments in Life Sciences pre- and post-intervention with virtual laboratory experimentation. To achieve this aim, the following objectives were set:

- $\quad$ To compare pre-service teachers' pre- and post- test attitudinal scores after virtual laboratory learning interventions.

- To assess pre-service teachers' receptiveness of virtual laboratory learning experiences. 
The afore-mentioned objectives enabled the researchers to answer the following research questions:

- How do pre-service teachers' attitudes towards virtual experimentation vary before and after learning interventions?

- To what extent are pre-service Life Sciences teachers receptive of virtual laboratory learning experiences?

\section{Theoretical Framework}

Active learning and student involvement in gaining conceptual understanding is an important aspect of learning biology concepts through inquiry (Lee \& Anderson, 2013). This engagement is accomplished when laboratory sessions (virtual or traditional) and investigations are included in the learning process to enhance the visualization of abstract concepts (Jian-Hua \& Hong, 2012). Underpinned by inquiry-based learning pedagogical strategies, experimentation is framed by cognitive and social constructivist theories of learning (Neo, 2007; Vygotsky, 1978). A set of integrative education theories which integrate technology, multiple media, and experimental learning in promoting science concept formation, better learning and eventually more positive attitudes towards a subject guided the learning interventions employed in the study.

As postulated by early constructivist theorists like Piaget and Dewey, experiential and experimental learning have the ability to enhance cognition significantly (Bruner, 1990; Neo, 2007). By implication, it is necessary for learners to be actively involved in investigating concepts, through the use of experiments and investigations in which they are active participants (Hsu et al., 2017; Lederman, 2009). The infusion of technology in $21^{\text {st }}$ century science learning, has provided applications whereby active learning can be done in virtual science laboratories. These virtually based science laboratories have enhanced science teaching and learning and played a significant role in learners' understandings of, visualization and engagement with abstract scientific concepts (Estapa \& Nadolny, 2015; Penn \& Ramnarain, 2019). In addition to the work of Piaget and Dewey, social constructivists advocate that learning is a social process (Vygotsky, 1978) and learning activities should be considerate of the learners' context and daily experiences (Mavuru \& Ramnarain, 2017). In the $21^{\text {st }}$ century and with the current boom of technological innovations, learning with technology constitutes a major part of students' attributes and must be incorporated in the learning of science subjects (Jian-Hua \& Hong, 2012; Lee \& Park, 2016; Swallow \& Olofson, 2017). The cognitive theory of multi-media learning also supports the postulates of cognitive constructivism in suggesting a positive relationship between visualization, interaction and the formation of mental schemas and representations (Mayer, 2011). The acquisition of adequate conceptual understandings propels students to show more positive attitudes in a particular subject or concepts and vice versa (Kaur \& Zhao, 2017; Wang et al., 2013). In consideration of these learning theories, open-source applications that motivate students' interest and engagement in virtual laboratory experimentation, were used. The main goal being to ensure that learning happens, and attitudes improve towards virtual experiments in Life Sciences.

\section{Virtual Laboratories}

Virtual laboratories are applications which provide alternative digital learning tools for inquiry-based science education (Hawkins \& Phelps, 2013; Makransky et al., 2019; Potkonjak et al., 2016). These applications can be used with mobile devices and computers directly online or offline depending on the model (Lee \& Wong, 2014). Several studies in science education have reported cognitive and affective gains with the use of virtual laboratories in learning (Hsu et al., 2017; Penn \& Ramnarain, 2019; Potkonjak et al., 2016). Students generally engage with these virtual laboratories by mouse clicks, swipes and immersive virtual reality controllers depending on the device and applications they use (Lee \& Wong, 2014; Makransky et al., 2019). Even though some of the virtual biology laboratories may not have highly immersive effects, they still provide an opportunity for students to engage interactively with simulators of reagents and apparati that would be found in a traditional Life Sciences laboratory (Stafford et al., 2010).

Virtual laboratories also provide a platform to experiment and manipulate different variables which is a step-up from traditional lectures and direct instructions (Clark et al., 2016; Merchant et al., 2014). One of the 
benefits of virtual laboratory experimentation is that creators like Pearson and kscience provide self-assessment quizzes to check students' understandings of concepts and enhance collaboration with their peers (Trundle \& Bell, 2010). These together with other benefits of virtual learning such as, learning autonomy, easy access to learning resources and convenience are some of the highlights that were exploited in the five-week learning intervention.

\section{Life Sciences Experiments}

For this research, participants investigated the factors that affected the rate of photosynthesis, rate of cellular respiration, evidence of $\mathrm{CO}_{2}$ production from the process of exhalation and other experiments as part of a five-week virtual learning intervention in Life Sciences. These concepts and factors usually require a traditional laboratory set-up for pre-service teachers to manipulate and control variables in order to collect real-time experimental data, that would help them to make logical conclusions based on the analysis of data which they collect. Figure 1 that follows is the screenshot and link to an open source photolab from kscience used by the participants to investigate the effects of temperature, light, and the concentration of $\mathrm{CO}_{2}$ on the rates of photosynthesis.

\section{Figure 1}

Screenshot from Photolab (http://www.kscience.co.uk/animations/photolab.htm)

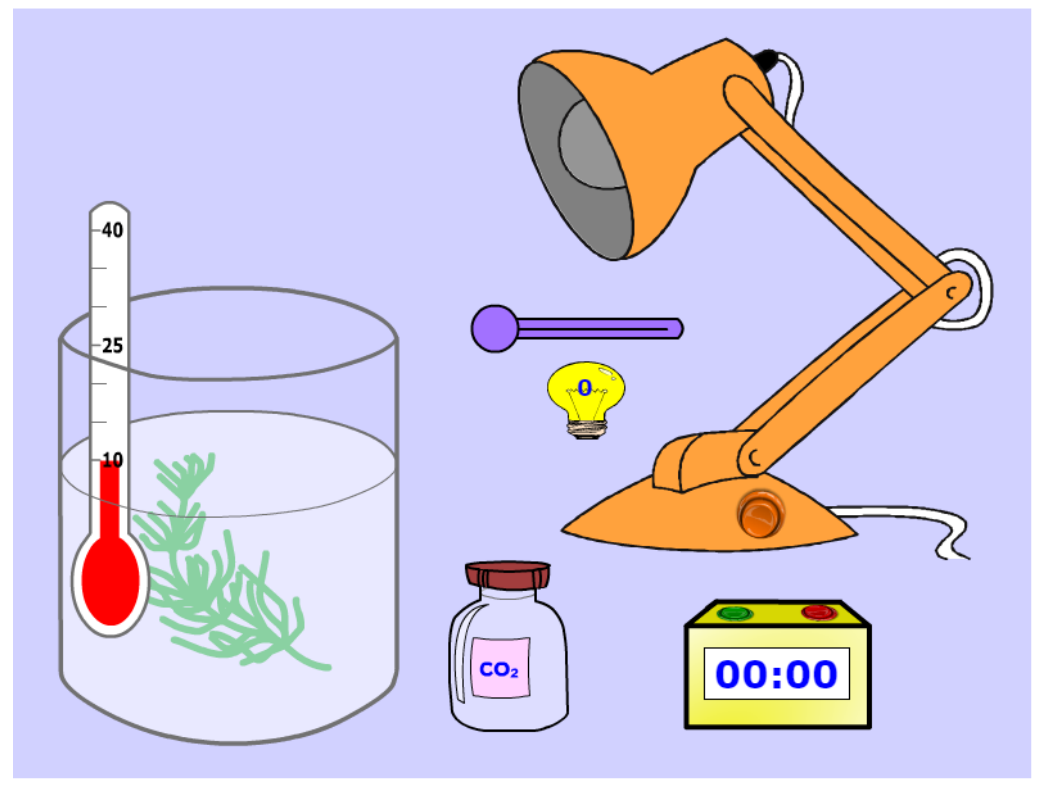

As shown in Figure 1, pre-service teachers were able to use the click of a mouse to manipulate the thermometer inserted in the beaker, which had the cut stem of a pondweed and sodium hydrogen carbonate solution. They were also able to change the light intensity, use the timer and increase the concentration of $\mathrm{CO}_{2}$ in the beaker through mouse clicks. These steps aided them to collect data for different light intensities and temperatures and proceed to calculate the rates of photosynthesis after manipulating the different factors. They measured the number of bubbles produced in 30-second intervals and plotted graphs as part of presenting their findings.

A similar experiment was followed in investigating the factors that affect the rates of respiration using an open-source Pearson education virtual laboratory. Figure 2 that follows shows a screenshot and link to the virtual laboratory used to investigate the effects of temperature on the rate of respiration. 


\section{Figure 2}

Screenshot of Factors that Affect the Rate of Respiration

(http://www.phschool.com/science/biology_place/labbench/lab5/analysis.html)

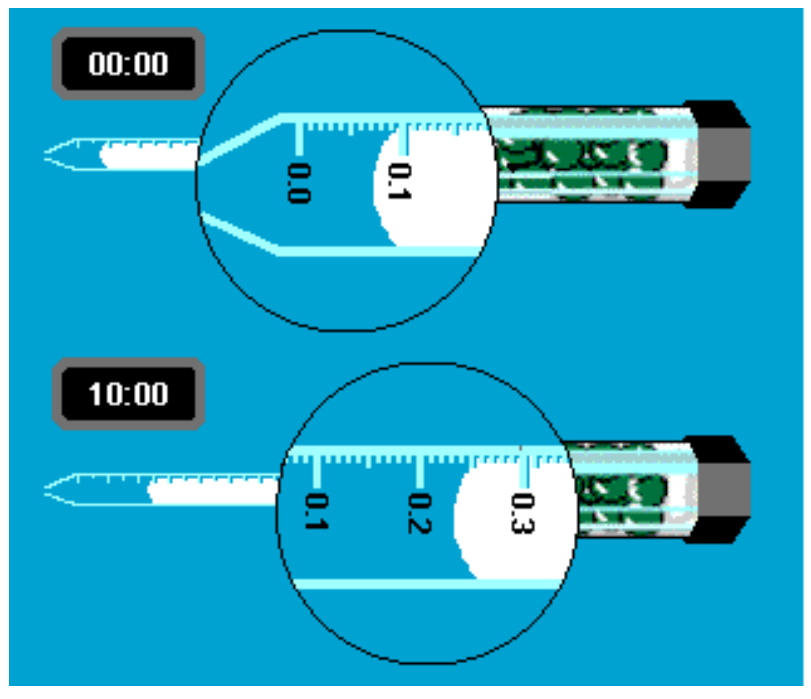

The screenshot in Figure 2 shows the collection of different amounts of oxygen consumed over time by nongerminating and germinating peas at different temperatures, keeping all other factors controlled. Pre-service teachers then compared the rates of respiration after plotting several readings (rate of respiration $=\Delta \mathrm{y} / \Delta \mathrm{x}$, where $\Delta \mathrm{y}$ is change in the volume of oxygen, and $\Delta \mathrm{x}$ is the change in time in minutes). The rest of the virtual laboratory investigations were completed in the same series over 5 weeks and several assessments followed.

\section{Research Methodology}

\section{General Background}

This research employed a sequential mixed method research methodology, whereby a quantitative survey was firstly used to assess pre-service teachers' attitudes before and after learning interventions with open-source virtual laboratories, followed by a qualitative inquiry targeted at elaborating on the findings from the quantitative phase (Creswell \& Creswell, 2018). Data was collected within a period of one year from 2019 to 2020 and limited only to a pre-service Life Sciences teachers in the third year of study.

\section{Sample}

The sample for the research, included 68 third year Life Sciences pre-service teachers at a South African tertiary institution of learning, purposively selected to participate in the study as part of their pre-service teacher development. The rationale for selecting this group was based on the fact that, third year is the final year in which students engage with Life Sciences content learning. The fourth year of the Bachelor of Education (B.Ed.) qualification mainly focuses on the development of pre-service teachers' pedagogical skills rather than the acquisition of content knowledge. The participants included 40 (58.8\%) female students and $28(41.2 \%)$ male students. The age of participants ranged between 20 and 25 years old with $66.2 \%$ of participants belonging to the age group $20-21$ years. Institutional ethical clearance was obtained for the research as well as voluntary individual student consent. The researchers ensured anonymity and confidentially and students were free to exempt themselves from the study at any given point without any repercussions. 


\section{Instrument and Procedures}

For the first phase of data collection which involved a quantitative inquiry, data were collected using the attitude towards virtual experimentation in biology (ATVEB) questionnaire. The ATVEB (appendix A) was adapted from the validated biology attitude questionnaire (Prokop et al., 2007) and modified by the researchers to include 25 questions and 5 constructs relevant for developing attitudes towards virtual biology experiments and not just the subject biology. The constructs within the questionnaire include: "Interest toward virtual biology experimentation; Future career in biology; Importance of virtual biology experimentation; Difficulty of virtual biology experimentation; and Equipment/images in virtual biology laboratory. Questionnaire responses included 5-point Likert scale responses from Strongly Disagree $=1$ to Strongly Agree $=5$ (see appendix A). All negative items were reverse scored during data analysis, with the total attitude scores possible ranging from 25-125. The ATVEB was first piloted with an alternative group of third year Life Sciences students from a different program prior to the commencement of the actual study. Thereafter the questionnaire was administered to participant students before and after five weeks of learning interventions with virtual biology experiments. In the second phase of the study, semi-structured focus group interviews were conducted with all participants of the study in their various study groups. The aim of these focus group discussions was to validate the post-test findings, attitude shifts from the quantitative phase of the research. Focus group discussions were preferred as they tend to be time and cost effective and provide a feasible solution for qualitative data gathering in participatory research (Cornwall \& Jewkes, 1995) as was the case in this research. The focus group discussions in this research were conducted with 10 focus groups involving all 68 participants, with groups ranging from 6-7 participants each. All groups consisted of students with mixed cognitive abilities, such that there was no imbalance in responses. The researchers together with an extra science education colleague facilitated the focus group sessions in the single focus groups approach (Morgan, 1996). Interviews ranged from 60-75 minutes long. The interviews helped in eliciting the participants' elaborations of their attitudes and experiences of using the virtual biology experiments thereby assessing their level of receptiveness with regards to virtual biology experiments. The interviews were audio recorded with the participants' consent and transcribed.

\section{Data Analysis}

The adapted ATVEB questionnaire was piloted with a third-year group of biological sciences students in the same institution who are not in the teacher education program. Results from the pilot study were used to calculate internal reliability/consistency and ensure the readability of the ATVEB questionnaire. Cronbach's alpha was calculated using the Statistical Package for the Social Sciences (SPSS) version 26. and $\nabla>.82$ was obtained for all constructs and was $>.72$ for all items. The pre- and post- intervention ATVEB scores were also analyzed and compared using SPSS. Data from the audio recorded focus group interviews were transcribed and analyzed using thematic content analysis to establish meanings and patterns (Leedy \& Ormrod, 2014). Before analyzing all 10 transcripts the researchers and a third science education specialists engaged in prior validation of $30 \%$ (three transcripts) by reading through the transcripts and coding them independently, then comparing the codes assigned in order to establish inter-coder reliability (Leedy \& Ormrod, 2014). By the end of this process the three independent coders, attained an inter-coder reliability above $80 \%$ agreement on the open codes assigned. The rest $70 \%$ of the transcripts were then open coded by the researchers with the aid of computer-assisted qualitative data analysis software (CAQDAS), Atlas.ti version 8.

\section{Research Results}

In answering the first research question, "how do pre-service teachers' attitudes towards virtual experimentation vary before and after learning interventions?", descriptive statistics was first used to analyze pre-service teachers' ATVEB scores before and after virtual learning interventions. Table 1 shows the sample means $(M)$ and standard deviations $(S D)$ of one of the questionnaire constructs "Interest towards virtual biology experimentation" for preand post-test side by side. 
Table 1

Pre- and Post-Intervention ATVEB Scores

\begin{tabular}{|c|c|c|c|c|c|}
\hline ATVEB construct/items & $N$ & $M$ & $S D$ & $M$ & $S D$ \\
\hline Interest towards virtual biology experimentation & \multicolumn{3}{|c|}{ Post-intervention } & \multicolumn{2}{|c|}{ Pre-intervention } \\
\hline 1. I like virtual experimentation biology more than other subjects & 68 & 3.7 & .81 & 3.1 & .83 \\
\hline 2. Virtual biology experimentation is strange to me & 68 & 4.0 & .63 & 2.96 & .90 \\
\hline $\begin{array}{l}\text { 3. I would like to have virtual experimentation in biology tasks } \\
\text { more often }\end{array}$ & 68 & 4.2 & .68 & 2.54 & 1.18 \\
\hline 4. I hate virtual laboratories in biology. & 68 & 4.1 & .51 & 3.06 & .98 \\
\hline $\begin{array}{l}\text { 5. The work with organisms and systems in virtual biology labora- } \\
\text { tories is very interesting }\end{array}$ & 68 & 4.5 & .65 & 2.63 & 1.24 \\
\hline
\end{tabular}

As shown in Table 1, pre-service teachers' mean ATVEB scores post-intervention for the sample items within the construct "interest towards virtual biology experimentation", were higher than pre-intervention ATVEB scores. Only one item, "my biology lecturer is my personal model, I would like to work like he/she does" recorded the same pre- and post-intervention ATVEB scores for the entire instrument. This indicated that there was little or no instructional or teacher influence on pre-service teachers' pre-and post-intervention attitudes. The increase in obtained postintervention mean scores was prominent across the other 4 constructs and 19 items of the questionnaire. Inferential statistics was employed in establishing whether the obtained post-test means were significantly different from the pre-test means at $95 \%$ confidence interval. After establishing that the data was normally distributed, the researchers proceeded to carry out a paired sample t-test to understand how significantly different the obtained means were. Results from the $t$-test confirmed that there was a significant difference between pre- and post-intervention ATVEB scores as seen in Table 2 that follows.

\section{Table 2}

Paired sample t-test

\begin{tabular}{ccccccc}
\hline Pair 1 & $\boldsymbol{N}$ & $\boldsymbol{M}$ & $\boldsymbol{S D}$ & $\boldsymbol{S E M}$ & $\boldsymbol{t}$ & $\boldsymbol{p}$ \\
\hline Pre-ATVEB scores & 68 & 60.52 & 5.35 & .76 & 12.33 & .001 \\
Post-ATVEB scores & 68 & 81.14 & 12.30 & 1.94 & & \\
\hline
\end{tabular}

As seen in Table 2, pre-service teachers' post-intervention attitude scores with the virtual laboratory experiments were significantly higher $(M=81.14, S D=12.30)$, than pre- intervention attitude scores $(M=60.52, S D=$ 5.35), $t(67)=12.33, p<.01$.

\section{Findings from Focus Group Interviews}

In answering the second research question "to what extent are pre-service Life Sciences teachers receptive of virtual laboratory learning experiences?", follow up semi-structured focus group interviews were conducted with all the participants. Findings from the analysis of qualitative data, revealed that students were receptive of virtual laboratories as part of their learning experiences. They found virtual laboratory experimentation quite useful in enhancing their learning of biology concepts. Table 3 that follows captures some of the interview questions, preservice teachers' responses in the form of quotations from different focus groups, and some meanings allocated to them during the coding and data analysis process. 
Table 3

Excerpts from focus group interviews

Semi-Structured Interview
questions Some quotations
What was your overall experience
of the virtual biology laboratories?
Please elaborate.
Virtual labs provided us with a new perspective. There were several "aha" moments. Indeed, we enjoyed the labs.

Our group found the virtual laboratories very convenient and easy to use. Imagine completing a lab task from the comfort of your house. That was good. They are actually really cost-effective. One did not have to come all the way to campus or look for any materials to use.
Enjoyment

Convenience

Cost-effective

Autonomy and self-directed learning.

Oh, yes, my attitude definitely changed for the best. I found myself repeating the lab tasks and just enjoying the process.

tions, did your attitude towards virtual experimentation in biology change? Why or Why not?

I also felt I could tackle more difficult and complex Life Sciences concepts

on my own.

We found it very easy to work on our own and still grasp the concepts without the assistance of the lab tutors.

What were some of the gains you observed with using the virtual laboratories in your experimentation?

The labs greatly enhanced our conceptual and procedural understandings as a group and even as individuals. We engaged seamlessly with inquiry tasks There were no time or material constraints, the labs were convenient. The learning activities were also helpful and many other benefits that we had already mentioned.

What fascinated me was that we could collect real-time data and control variables, wow! Inquiry in my computer.

I have no fear of making errors with the virtual labs

You try different things in the virtual laboratories without fear of spoiling anything.

The ability to do several different activities increased my confidence to deal with the problems from my Life Sciences lectures.

What were some of the disadvantages of using virtual experimentation in biology in your own view?
I felt that the actual real Life Sciences process skills would not be acquired if we have to experiment like this.

I actually agree with ... because in Life Sciences it is crucial to be able to manipulate, measure, handle equipment and sharp objects in real life. The simulations create some misconceptions.

The virtuality of the labs makes the experience to lack realness. You cannot compare it to the actual lab even though it exposes one to what we would do in the actual real-life experiment.
Both understandings and inquiry were enhanced No constraints

Hypothesis testing was

enhanced

Increased confidence in problem solving.

Poor development of science process skills.

Possible misconceptions created. Lack of authenticity

As seen from the assigned quotations and meanings in Table 3 above, the key themes generated from these categories were: i) Virtual experiments provided convenience and ease of access to experimental learning resources from anywhere; ii) Students' conceptual and procedural understandings of Life Sciences concepts were enhanced during the virtual laboratory learning interventions; and iii) Autonomous and self-directed learning was well supported. Other assertions generated included, enjoyable learning experiences using virtual experiments, the costsaving affordance of virtual experimentation, and the ultimate enhancement of inquiry-based learning especially hypothesis testing. On the other hand, participants noted shortcomings related to the lack of authenticity, which is typically experienced in a traditional biology laboratory. Some groups of pre-service teachers also noted that while the mouse clicks engaged them in understanding the scientific procedures related to the investigations given, it would be difficult to acquire basic and integrated science process skills by only engaging in virtual experimentation. Overall, pre-service teachers were quite excited and receptive of virtual laboratories in enhancing their learning experiences. During the focus group interviews pre-service teachers' responses towards the attitude constructs were further verified to validate the patterns observed in the pre- and post-test as explained below. 


\section{Interest towards Virtual Experimentation}

When asked to explain their interest towards the use of virtual experimentation post learning interventions, eight of the 10 focus groups indicated that prior to the learning interventions, they did not know the extent to which they could use virtual laboratories and simulations for Life Sciences experiments and other investigations. Hence, the experiences were novel to them and stimulated curiosity. Some members of the two remaining focus groups indicated that they had used similar virtual laboratories prior to the learning intervention. All 10 groups found the inclusion of virtual laboratories to be a useful and relevant pedagogical tool, which could seriously enhance learning in this digital age.

\section{Future Career}

When asked if virtual laboratories were something they would consider including in their pedagogical practices post the attainment of the B.Ed qualification, all 10 focus groups indicated that they would certainly infuse virtual laboratories as part of their Life Sciences teaching going forward because they could relate to the possible learning gains. Though some of them noted that these virtual laboratories could not replace the need and relevance of traditional science laboratories, they found them to be worthy tools in the hands of any aspiring Life Sciences teacher. They also indicated their excitement for the teaching profession ahead.

\section{Importance of Virtual Experimentation}

For this construct, what stood out from the focus group interviews included the ability to visualize and at the same time carry out experiments which led to the collection of real-time data. The pre-service teachers indicated that virtual experimentation was very relevant in aiding with hypothesis testing and could be used to prepare for traditional laboratory sessions in anticipation of the experiments they will be conducting.

\section{Difficulty associated with Virtual Experimentation}

All 10 focus groups indicated that they did not find it difficult to use the virtual laboratories. The instructions and clicks were easy to follow after the introductory session. Also, none of the participants indicated any computer related discomforts related to screen lighting. However, in the last focus group session some of the individual group members expressed that there were aspects of the virtual laboratory which confused them. For instance, one participant pointed out that he found some images from the virtual laboratory for temperature versus rate of respiration to create some misconceptions initially, but this was clarified by one of his group peers at a later stage.

\section{Equipment/images in Virtual Biology Laboratory}

All 10 focus groups indicated that they enjoyed the enhanced visualization provided by the virtual laboratories. Participants indicated that they were also excited about the affordances of planning and conducting experiments using virtual equipment, which needed no preparation time and eliminated laboratory hazards.

\section{Discussion}

The findings from this study revealed that virtual laboratory experimentation in the Life Sciences is a worthy tool to enhance not only students' attitudes but also their procedural and conceptual understandings of science concepts in general and biology concepts in particular. As seen in the findings of this study, it is clear that the virtual learning interventions had a positive effect on pre-service teachers' reception of and attitudes towards virtual laboratory-enhanced Life Sciences learning. Pre-service teachers elaborated that, virtual learning resources made learning easier and enhanced their conceptual understandings of Life Sciences concepts. Another aspect highlighted was the learning autonomy and accessibility to virtual laboratories from anywhere and anytime, which facilitated learning during spare times. Other factors that might have affected the participants' attitudes including the nature of instruction or learning environment were not assessed for this study. This could easily pose as a 
limitation to the study, but the researchers ensured that the instructor stayed constant and quantitative findings were also elaborated on by triangulating with qualitative data gathering.

Reverting to literature, the current findings are similar in many ways to findings from other studies, which employed virtual laboratories in enhancing students' learning experiences, attitudes, motivation and even career choices in science. For instance, in a study by Stafford et al. (2010), the researchers found that, experimentation using virtual simulations could be the best tool for teaching experimentation in ecological studies. Similar to the findings of this current study, Stafford et al. (2010), noted that students found virtual experimentation rather costeffective. Several other studies across different science subjects (Chua \& Karpudewan, 2017; Estapa, \& Nadolny, 2015; Hsu, et al., 2017; Merchant et al., 2014; Penn \& Ramnarain, 2019) found that virtual experimentation was positively beneficial for enhancing attitudes, motivation, procedural and conceptual understandings of science concepts across subjects. In principle the findings of this study also show that while social distancing and maintaining the recent COVID-19 pandemic regulations, students can still experiment online and collaborate with their peers while doing so (Vasiliadou, 2020). From the findings of studies like Chen (2002) and Hsu et al. (2017) also revealed in the current study, though virtual learning has its place in science education, it cannot be a replacement for traditional laboratory-based learning. The pre-service teachers themselves acknowledged the missing elements of authenticity in their virtual learning experience, a finding that concurs with the findings from Hsu et al. (2017). It is therefore important that virtual experiments complement the actual manipulation and handling of microscopes, stains, solutions, lenses, and specimens as should be the case in laboratory-based Life Sciences learning. Contrary to the findings in this study, a study by Faour and Ayoubi (2018), reported no attitude changes in a grade 10 students' attitudes towards physics post-intervention with virtual laboratory, while an even older study by Payne (2005) found that 53\% of the participant students did not endorse virtual learning. This indicates that though certain technological tools may be innovative, students may tend not to prefer it and it may not necessarily make a difference in the teaching and learning of science concepts. From the semi-structured focus group interviews, the pre-service teachers indicated that they derived several benefits from using the virtual laboratory experiments when learning Life Sciences and were quite receptive of the approach. Gains included easy access to global learning resources, cost effectiveness, and enhancement of autonomous and inquiry-based learning. All of the gains from this learning intervention are indicative of the possibilities that virtual laboratory life science learning present for both teaching and learning.

\section{Conclusions and Implications}

Based on the findings of this study, it is clear that, experimentation in virtual laboratories may not be able to replace hands-on authentic laboratory learning experiences, but can be used to complement traditional IBL practices in Life Sciences education by enhancing pre-service teachers' attitudes towards the subject. The technological affordances of virtual learning integrated with traditional approaches has the ability to improve students' attitudes and conceptual understandings of Life Sciences concepts.

The findings from this study have several implications for Life Sciences education within and post the COVID-19 pandemic. As observed in the current global disposition, the effects of the COVID -19 pandemic pose a serious threat to social interactions, interactive and collaborative learning, which are the fundamentals of IBL and experimentation. While teachers and students observe social distancing in their learning spaces, it will become increasingly difficult to engage in IBL as a whole, whether by experimentation or otherwise. Virtual laboratory applications therefore present an excellent complementary tool to enhance students' visualization of scientific concepts and the ability to be able to individually or collaboratively manipulate variables from the comfort of their own private spaces. We note that even though virtual laboratories cannot replace traditional biology laboratories, they are bound to come in handy at this time in enhancing learning.

The main contribution of this study lies in establishing the possibility of integrating virtual laboratories in Life Sciences learning as tools to enhance students' attitudes towards laboratory learning. The findings of the study also suggest that virtual laboratories are a worthwhile tool and learning resource in science classrooms in general. Hence science teachers and teacher educators should consider the systematic integration of virtual laboratory tools as part of their pedagogical strategies in training learners and pre-service science teachers for classrooms of the future, respectively. It is becoming increasingly obvious in this fourth industrial revolution and the start of a decade plagued by the COVID -19 pandemic that teachers who do not have a sound technological pedagogical knowledge (TPK) could lose their relevance in the teaching profession. Therefore, the times present 
an opportunity for the uptake and implementation of new virtual learning strategies in science curricula globally. For future studies it is recommended that a comparative study which examines side by side attitudinal changes as they relate to traditional laboratory-based versus virtual biology laboratory-based be considered. Larger scale studies across different science subjects and contexts on the affordances and effects of virtual experimentation on student achievement, motivation towards science and science technology engineering and mathematics (STEM) career choices as a whole could be a worthy endeavor to assess the effectiveness of virtual laboratories.

\section{Acknowledgements}

The authors sincerely appreciate Pearson's education and Kscience for providing several open- source virtual learning resources for science learning.

\section{References}

Bruner, J.S. (1990). Acts of meaning. Harvard University Press.

Can, H. B. (2012). Students' attitudes toward school chemistry: The effect of interaction between gender and grade level. AsiaPacific Forum on Science Learning and Teaching, 13(1), 1-16. https://eric.ed.gov/?id=EJ990378

Chen, K. Y. (2002). Thinking IT simulations for interactivity, thinking and assessment in science education. Teaching and Learning, 23(1), 85-97.

Chua, K. H., \& Karpudewan, M. (2017). The role of motivation and perceptions about science laboratory environment on lower secondary students' attitude towards science. Asia-Pacific Forum on Science Learning and Teaching, 18(2), 1-16. https://eric. ed.gov/?id=EJ1179318

Clark, B. D., Tanner-Smith, E. E., \& Killingsworth, S. S. (2016). Digital games, design, and learning: A systematic review and metaanalysis. Review of Educational Research, 86(1), 79-122. https://doi.org/10.3102/0034654315582065

Cornwall, A., \& Jewkes, R. (1995). What is participatory research? Social Science and Medicine, 14, 1667- 1676.

Creswell, J. W., \& Creswell, J. D. (2018). Research Design: Qualitative, quantitative, and Mixed Methods (6 ${ }^{\text {th }}$ ed.). Sage.

Department of Education. (2004). Draft white paper on e-Education. Transforming learning and teaching through Information and Communication Technologies (ICTs). https://www.gov.za/sites/default/files/26734_1.pdf

Duyilemi, A. N., Olagunju, A. M. \& Olumide, O. J. (2014). Effects of computer simulation package, gender and parental education on Nigerian secondary school students' attitude towards biology. Paper presented at the 21st Century Academic Forum Conference Proceedings, Harvard. https://www.21 caf.org/uploads/1/3/5/2/13527682/duyilemi-hrd-conference_proceedings.pdf

Estapa, A., \& Nadolny, L. (2015). The Effect of an augmented reality enhanced mathematics lesson on student achievement and motivation... Journal of STEM Education, 16(3). https://www.learntechlib.org/p/151963/.

Esquembre, F. (2015). Facilitating the creation of virtual and remote laboratories for science and engineering education. IFACPapers Online, 9(1), 49-58. https://doi.org/10.1016/j.ifacol.2015.11.212.

Faour, M. A., \& Ayoubi, Z. (2018). The effect of using virtual laboratory on grade 10 students' conceptual understanding and their attitudes towards physics. Journal of Education in Science, Environment and Health (JESEH), 4(1), 54-68. https://doi:10.21891/jeseh.387482

Francis, L. J., \& Greer, J. E. (1999). Attitude toward science among secondary school pupils in Northern Ireland: relationship with sex, age and religion. Research in Science and Technological Education, 17(1), 67-74. https://doi.org/10.1080/0263514990170105

Großmann, N., \& Wilde, M. (2019). Experimentation in biology lessons: guided discovery through incremental scaffolds. International Journal of Science Education, 41(6), 759-781. https://doi:10.1080/09500693.2019.1579392.

Hawkins, I., \& Phelps, A. (2013). Virtual laboratory vs. traditional laboratory: Which is more effective for teaching electrochemistry. Chemistry Education Research and Practice, 14(4), 516-523. https://doi.org/ 10.1039/C3RP00070B.

Holtzclaw, T. K. (n.d). http://www.phschool.com/science/biology_place/labbench/lab1/intro.html.

Hsu, Y. S., Lin, Y.-H., \& Yang, B. (2017). Impact of augmented reality lessons on students' STEM interest. Research and Practice in Technology Enhanced Learning, 12(2), 1-14. https://doi.org/ 10.1186/s41039-016-0039-z.

Jian-Hua, S., \& Hong, L. (2012). Explore the effective use of multimedia technology in college physics teaching. Energy Procedia, 17, 1897 - 1900. https://doi.org/10.1016/j.egypro.2012.02.329.

Kaur, D., \& Zhao, Y. (2017). Development of Physics Attitude Scale (PAS): An Instrument to Measure Students' Attitudes toward Physics. Asia-Pacific Education Researcher, 26(5), 291-304. https://doi.org/ 10.1007/s40299-017-0349-y.

Koballa, T.R., \& Crawley, F.E. (1985). The influence of attitude on science teaching and learning. School Science and Mathematics, 85(3), 222-232. https://doi.org/ 10.12691/education-2-11A-2.

Kscience. (n.d). (2010). http://www.kscience.co.uk/animations/photolab.htm

Lederman, J. S. (2009). Teaching scientific inquiry: Exploration, directed, guided, and opened-ended levels. http://ngl.cengage.com/ assets/downloads/ngsci_pro0000000028/am_lederman_teach_sci_inq_scl22-0439a.pdf. 
Lee, E. A., \& Wong, K. W. (2014). Learning with desktop virtual reality: Low spatial ability learners are more positively affected. Computers \& Education, 79, 49-58.

Lee, H. S., \& Anderson, J. R. (2013). Student learning: What has instruction got to do with it? Annual Review of Psychology, 64, 445-469. https://doi.org/10.1146/annurev-psych-113011-143833

Lee, J., \& Park, H. (2016). A Study on cases for application of flipped learning in K-12 education. Journal of Digital Convergence. 14(8), 19-36. https://doi.org/10.14400/JDC.2016.14.8.19

Leedy P. D. and Ormrod J. E., (2014). Practical Research: Planning and Design (10 $0^{\text {th }}$ ed). Pearson.

Makransky G., Terkildsena T. S., \& Mayer R. E. (2019). Adding immersive virtual reality to a science lab simulation causes more presence but less learning. Learning and instruction, 60, 225-236. https://doi: 10.1016/ j.learninstruc.2017.12.007.

Mavuru, L., \& Ramnarain, U. (2017). Teachers'Knowledge and Views on the Use of Learners'Socio-cultural Background in Teaching Natural Sciences in Grade 9 Township Classes. African Journal of Research in Mathematics, Science and Technology Education, 21(2), 176-186. https://doi.org/:10.1080/18117295.2017.1327239.

Mayer, R. E. (2011). Instruction based on visualizations. In R.E. Mayer \& P.A. Alexander (Eds.), Handbook of Research on Learning and Instruction. Routledge.

Merchant, Z., Goetz, E. T., Cifuentes, L., Keeney-Kennicutt, W., \& Davis, T. J. (2014). Effectiveness of virtual reality-based instruction on students' learning outcomes in K-12 and higher education: A meta-analysis. Computers \& Education, 70, $29-40$. https://doi.org/10.1016/j.compedu.2013.07.033.

Morgan, D. L. (1995). Why things (sometimes) go wrong in focus groups. Qualitative Health Research, 5, 516- 523.

Naidoo, J. \& Paideya, V. (2015). Exploring the possibility of introducing Supplemental Instruction at secondary school level. South African Journal of Education, 35(2). https://doi.org/ 10.15700/saje.v35n2a1022

National Research Council. (2012). A framework for K-12 science education:Practices, crosscutting concepts, and core ideas. National Academy Press.

Neo, M. (2007). Learning with multimedia: engaging students in constructivist learning. International Journal of Instructional Media, 34(2), 149-158.

O'Brien, J., \& Porter, G. C. (1994). Girls and physical science: The impact of a scheme of intervention projects on girls' attitudes to physics. International Journal of Science Education, 16(3), 327-341.

Otor, E. E., \& Achor, E. E. 2013. Effect of concept mapping strategy on students' attitude in difficult chemistry concepts. European Journal of Educational Sciences, 1(3), 116-124.

Payne, R. (2005). Classroom: For the Next Century, Computer \& Internet Communication. Hampton Press.

Penn, M., \& Ramnarain, U. (2019). South African university students' attitudes towards chemistry learning in a virtually simulated learning environment. Chemistry Education Research and Practice, 4(20), 699-709. https:// doi.org/ 10.1039/c9rp00014c.

Perloff, R. M. (2016). The Dynamics of Persuasion: Communication and Attitudes in the Twenty-First Century. Routledge.

Potkonjak, V., Gardner, M., Callaghan, V., Mattila, P., Guetl, C., Petrović, V.M., \& Jovanović, K. (2016). Virtual laboratories for education in science, technology, and engineering: A review. Computers \& Education, 95, 309 -327. http://dx.doi.org/10.1016/j.compedu.2016.02.002.

Prokop, P., Tuncer, G. \& Chuda, J. (2007). Slovakian students' attitudes towards biology. Eurasia Journal of Mathematics, Science \& Technology Education, 3(4), 287-295. https://doi.org/10.12973/ejmste/75409.

Simpson, R.D., \& Oliver, J.S. (1990). A summary of major influences on attitude toward and achievement in science among adolescent students. Science Education, 74, 1- 18.

Stafford, R., Goodeough, A. E., \& Davies, M. S. (2010). Assessing the effectiveness of a computer simulation for teaching ecological experimental design. Bioscience Education, 15(10), 1-9. https://doi.org/10.3108/beej.15.1.

Swallow, M.J.C, and Olofson, M. W., 2017. Contextual Understandings in the TPACK Framework. Journal of Research on Technology in Education, 49(3), 228-244.https://doi: 10.1080/15391523.2017.1347537.

Trundle, K.C., and Bell, R.L. 2010. The use of a computer simulation to promote conceptual change: a quasi- experimental study. Computers \& Education,54(4),1078-1088. https://doi.org/10.1016/j.compedu.2009.10.012.

Umar, A. A. (2011). Effects of biology practical activities on students' process skill acquisition in Minna, Niger State, Nigeria. Journal of Science, Technology, Mathematics and Education, 7(2), 118-126.

Vandeyar, T. (2015). Policy intermediaries and the reform of e-Education in South Africa. British Journal of Educational Technology, 46, 344-359. https://doi.org/10.1111/bjet.12130.

Vasiliadou, R. (2020). Virtual laboratories during coronavirus (COVID-19) pandemic. Biochemistry Molecular Biology Education, 48 (5), 482-483. https://doi.org/10.1002/bmb.21407VASILIADOU 483

Vygotsky, L. S. (1978). Mind in Society: The Development of Higher Psychological Processes. (Cole, M.M. Lopez-Morillas, Luria, A. R \& Wertsch, J.Trans.). Harvard University Press.

Wang, Z. W., Li, S. A., Yang, L., \& Hao, A. (2013). Real-Time CUDA Based Collision detection and Physics based collision response simulation. AWERProcedia Information Technology \& Computer Science. [Online], 3, 1834-1839. http://www.world-educationcenter.org/index.php/P-ITCS 


\section{Appendix A: Attitude towards Virtual Experimentation in Biology (ATVEB)}

This questionnaire contains 25 items in which evaluate your attitude towards virtual experimentation in life sciences (a.k.a Biology). All responses should be based on your own personal experiences in life sciences learning as this is not a test. The researcher (s) values your honest input, as this will go a long way in informing pedagogical practices in the life sciences.

Please read the item carefully and circle your most appropriate response from the responses below; Read the statements carefully. Your response choices for all items include:

Strongly Agree-5, Agree-4, Neutral-3, Disagree-2, Strongly Disagree-1

If you make an erroneous selection cross it with an " $x$ " and circle the new correct response.

Anonymity and confidentiality are important to the researcher (s). Nothing, about your response will be publicised to directly identify you.

Section A: demographic information

Gender Date: Age

Level of study:

Race:

Possible responses: Always $=5$, Very often $=4$, Sometimes $=3$, Rarely $=2$, Never $=1$

\begin{tabular}{|c|c|}
\hline Constructs/ Questions & Responses \\
\hline \multicolumn{2}{|l|}{ Interest toward virtual biology experimentation } \\
\hline 1. I like virtual experimentation biology more than other subjects & 54321 \\
\hline 2. Virtual biology experimentation is strange to me & 54321 \\
\hline 3. I would like to have virtual experimentation in biology tasks more often & 54321 \\
\hline 4. I hate virtual laboratories in biology & 54321 \\
\hline 5. The work with organisms and systems in virtual biology laboratories is very interesting & 54321 \\
\hline \multicolumn{2}{|l|}{ Future career in biology } \\
\hline 6. I like teaching biology based on my virtual learning experiences & 54321 \\
\hline 7. I would like, therefore, make a career in this field & 54321 \\
\hline 8. Experimental biology knowledge is necessary for my future career & 54321 \\
\hline 9. My biology lecturer is my personal model. I would like to work like he/she does & 54321 \\
\hline 10. My future career is independent on my experiences with virtual biology learning & 54321 \\
\hline 11. I would like to be a biology teacher & 54321 \\
\hline
\end{tabular}




\begin{tabular}{|c|c|}
\hline Constructs/ Questions & Responses \\
\hline 14. Virtual biology experimentation is essential for understanding other courses and phenomenon & 54321 \\
\hline 15. Nobody needs the knowledge of virtual biology laboratories & 54321 \\
\hline 16. The use of virtual experimentation in biology improves pedagogic practices & 54321 \\
\hline \multicolumn{2}{|l|}{ Difficulty of virtual biology experimentation } \\
\hline 17. I often have difficulties in understanding what we have learn in virtual biology experimentation & 54321 \\
\hline 18. Virtual biology investigations are easy for me & 54321 \\
\hline 19. I like the way virtual experimentation in biology assist my learning & 54321 \\
\hline 20. I find it stressful to engage in virtual biology learning tasks & 54321 \\
\hline 21. The use of computer screens in virtual biology experimentation cause a problem for me & 54321 \\
\hline \multicolumn{2}{|l|}{ Equipment/images in virtual biology laboratory } \\
\hline 22. Virtual images in biology experiments are appealing to my senses & 54321 \\
\hline 23. I don't find any virtual images or equipment appealing to my senses & 54321 \\
\hline 24. I am afraid to use the virtual laboratory equipment than the traditional ones & 54321 \\
\hline 25. I enjoy the visual effects of the images in virtual biology laboratory & 54321 \\
\hline
\end{tabular}

\begin{tabular}{cl}
\hline Mafor Penn & MEd, Lecturer, Department of Childhood Education, Faculty of Education, \\
(Corresponding author) & University of Johannesburg, GNA229, Robert Sobukwe, SWC campus, \\
& South Africa. \\
& E-mail: mpenn@uj.ac.za \\
& Website:https://scholar.google.com/citations?user=hLB26McAAAAJ\&hl=en \\
& ORCID: https://orcid.org/0000-0001-6217-328X \\
& PhD in Science Education, Senior Lecturer, Department of Science and \\
& Technology Education, Faculty of Education, University of Johannesburg, \\
& BR 404A, Cnr Kingsway Ave and University Rd, Auckland Park, \\
& Johannesburg, 2006, South Africa. \\
& E-mail: lydiam@uj.ac.za \\
Website: https://www.uj.ac.za/contact/Pages/Lydia-Mavuru.aspx \\
ORCID: https://orcid.org/0000-0001-9099-0746
\end{tabular}

